\title{
William Pinar Responding to Elliot Eisner Milwaukee, 1976
}

\author{
Transcribed and Introduced by Fernando M. Murillo
}

\section{Fernando M. Murillo}

Pontificia Universidad Católica de Chile

From the late 1960s, scholars in the field of curriculum (most notably Paul Khlor, Dwayne Huebner, William Pinar, among others), took up the work of rethinking the field, working from the traditions of the humanities. As Sam Rocha notes, they "sought to awaken the field of education out its social scientific slumber and point to a vision of curriculum that was not limited by the near sightedness of the institutional school" (Murillo 2018, vi). But the field of education does not wake up that easily, and an epochal change within a field happens only gradually.

However, and by paying attention to the intellectual history of a field, we learn that sometimes, certain particular events prove to be decisive in the shift or acceleration of the trajectory of change. The text you are about to read is an example of such an event. While other scholars had already began the work of reconceptualizing curriculum, hinting at its significance for the formative experience of the human person (rather than as a tool for institutional management), it is not until 1976 when, partially inspired by Huebner's work, a young William Pinar marks a definitive shift in curricular studies in a move away from attention to schooling and toward subjectivity instead.

During a conference on curriculum theory - one attended by Ralph Tyler and Elliot Eisner - Pinar read what proved to be a controversial paper in response to both the traditional and the seemingly progressive approaches to curriculum. In what was

ISSN 2560-8371

DOI: 10.24908/encounters.v20i1.13558

(C) Encounters in Theory and History of Education | 159 
considered an avant-garde theoretical position, he reframed the reconceptualist approach as one that rejected the "intellectual imperialism of the social sciences in the field of education" and felt "disdain for experiments and other contemporary forms of pseudo-empiricism." Further, he made a clear distinction between education and schooling, a distinction that has proved to be crucial in the re theorizing of the field.

"What is practiced in schools often bears little or no relation to the process that is education," Pinar asserts, positing educational experience as the primary interest of a reconceptualised view of curriculum. Education, in contrast to schooling, is conceived as a broad concept, one that is mediated fundamentally by one's own biographic situation. As such, to talk about education means to talk about the "intellectual and psychosocial development of individuals," to pay attention to "body and feeling," to refer to the self-initiated discipline of study, and, overall, to the experience of subjective reconstruction and transformation.

From a perspective of intellectual history, I claim that it is with this paper that Pinar provoked a turning point in the field of curriculum studies, one that brought the focus of attention back to the subjectively existing individual at the center of educational experience and opened the way for a more careful and dedicated consideration of the problem of subjective reconstruction.

While this notion was foreshadowed by Huebner, it is in this presentation that Pinar articulates clearly the importance of the concrete subject: a flesh and blood person appears. In this sense, the field of curriculum studies returns, however inadvertently at this point, to the continental views on education as formation.

The paper that follows was read by William Pinar in 1976 at the Curriculum Conference in Milwaukee (United States). It is a response to a paper presented by Elliot Eisner titled "The Curriculum Field Today: Where We Are, Where We Were, and Where We Are Going." In the words of Pinar, this paper was not much a response as it was a "confrontation." The event, Pinar confides, turned Eisner into a lifelong enemy.

This paper got lost and was never published, but luckily a recording of it survived the test of time. I transcribed it here to make it available.

Today, and as the field of education has gone back to its slumber under the trance of screens, fantasies of methods for effective teaching and learning, and practices of standardization, returning to the original spirit of the reconceptualization is now an ethical necessity. It is indeed in looking to the past that we can think of a future in education, one that is attentive to the inner life of the subject, and to the reconstruction of the spirit of a nation.

As you study this text, gentle reader, see for yourself in what ways the ideas offered here might awaken you. 


\section{Reference}

Murillo. Fernando M. 2018. A Lacanian Theory of Curriculum in Higher Education: The Unfinished Symptom. Gewerbestrasse, Switzerland: Palgrave.

\section{Response to Elliot Eisner}

\section{William Pinar \\ University of British Columbia}

Reading your paper is reading a letter addressed to someone else. On page 8 you write, "we often find it uncomfortable to refer to ourselves as scholars." I do not. For me, for those I know well in this field, scholar is a primary identity. Also, on page 8, "we hear from our colleagues that our field is moribund, even we, from time to time, pronounce ourselves on the verge of death." Those of us, including prominently Dwayne Huebner and Paul Khlor, who have reported this field as moribund, we are colleagues. We are not included in the "we" in the second sentence, the "we" who was you and your readers. Reading someone's letter to someone else, I'm an outsider. Outside of the interpersonal context out of which the author speaks. As outsider, it feels inappropriate to speak. Instead I wish to quickly reseal the envelope and forget what I read. I can't. The curriculum field is the theme of the letter, and this is my field also, so I write my response to you.

The issues you raise are prominently your own issues. They are no longer mine, except as others occasionally raise them to me. I and my generational contemporaries took seriously during our graduate studies your, and others, like Kliebard's, criticism of pseudo-scientific models of education. We saw how little the work of Magar Magar, Popham, and others had to do with the process of education. We saw how inappropriate popular models of evaluation were. We saw the intellectual imperialism of the social sciences in the field of education and we took seriously your and others', like Huebner's, Khlor's, MacDonald's, call for multidisciplinarity in educational research. We came to respect "think pieces" and even felt disdain for experiments and other contemporary forms of pseudo-empiricism. Performance-based models clearly were politically motivated, intellectually naïve and inappropriate. Taking jobs upon completion of degrees, we found the state of the system you mention on page 20, but those I know have not been intellectually seduced.

We left behind the issues you outline on your paper and took our next steps. These steps were grounded in the arts, in phenomenology, critical theory, as you call for in pages 27 through 29.

The future you envision, Mr. Eisner, is now. 
We, your intellectual children, grew up with your critiques, with your commitments, and we worked hard in our own ways to honor them.

What angers is that in your letter to your peers, you did not acknowledge our presence. Why not?

The answer lies in our now different conceptions of the curriculum field and in our different investments, intellectual and psychological, in this field. Understanding these, your letter becomes intelligible, and our new positions vis a vis each other become clear.

On page 1 you write, "Even if we wanted to, none of us who work in the field of curriculum are able to isolate ourselves from the problems of educational practice. What happens in schools is part of the subject matter we study. It provides incentive and direction to our work. It informs the field from which our aspirations and irritations as professional students of education are drawn."

First, one must to distinguish between educational practice and schooling. They are not necessarily identical. As you know, what happens is schools bears little or no resemblance to the process that is education. By naming ourselves curricularists, we disclose our interest in the role of curriculum in the educative process. This means encompassing most definitions with currency today, examining the role of text, teachers, and activities in the intellectual and psycho-social development of individuals. To study this relation, say between text and intellectual development, may indeed require one to stay away from schools. In fact, if it is the educative process in which we are interested, we are wise to stay away from schools.

Of course, if it is schooling which intrigues and, say, the role of materials and the socialization of school children, then clearly it is sensible to focus on schools. But it is by no means self-evident that curricularists must be involved physically and intellectually in schools.

The involvement in schools discernible in your paper and in many of your generational contemporaries is of a different order of the involvement just described.

For you, "what happens in schools provide incentives and direction to our work, it informs the field from which both our aspiration and irritations are drawn". For you what happens in schools is the ground of the curriculum field, in fact, it sounds as if it is the curriculum field. Given the use of the words "aspirations" and "irritations", what happens in schools is emotionally significant. Your subsequent examination of the current scene of the American schooling underlines this emotional investment. I, for one, have ceased caring what happens in the public schools in the way you seem to care. It is not surprising that "we curricularists have not had much impact upon the conduct of school practice" (p. 7). And it is not because we have had an inadequate political base, or because our status is not what educational psychologists' is.

To imagine that any one group could significantly alter institutions as deeply reflective of American culture as the public schools is either accept however 
unconsciously a technological view of social change, or to be politically naïve of the effects organized groups can have on institutional reformation.

The former idea, that by altering curriculum content or its organization or the design of courses, or the intentions of teachers, one can make important modifications. The analog is that an engine is malfunctioning and only if we identify the problem parts, repair or replace them, the engine can function smoothly.

You would deny holding such a mechanical conception of institutional change, but by what other rationale would one think curricularists could alter what happens in schools. The latter view is that organized groups, think of labour unions, can force basic structural change in the social order. I doubt you take such a singly political view of the role of curricularists in altering what happens in schools, but it may be an ingredient in your view. What happens in schools cannot be transformed by any group or coalition of groups. What happens in schools reflects the deep structure of our culture, our...only semiconscious view of our children, that they must be controlled and molded, our cultural preoccupations with competition, advancement in one form or another, with work, and with material objects.

Schools will never change the social order, even if they dare to try. Just as curricularists will never significantly change schools. Historical movement occurs not so simply.

Tolstoi, in War and Peace, challenges the similarly simplistic view historians held of the 1812 French invasion of Russia. He writes,

Man's mind cannot grasp the causes of events in their completeness, but the desire to find them is implanted in man's soul. And without considering the multiplicity and complexity of the conditions any one of which taken separately may seem to be the cause, he snatches at the first approximation to a cause that seems to him intelligible and says: "This is the cause!" In historical events...the first and most primitive approximation to present itself was the will of the gods and, after that, the will of those who stood in the most prominent position - the heroes of history. But we need only penetrate to the essence of any historic event - which lies in the activity of the general mass of men who take part in it - to be convinced that the will of the historic hero does not control the actions of the mass but is itself controlled.

There are laws directing events, and some of these laws are known to us while we are conscious of others we cannot comprehend. The discovery of these laws is only possible when we have quite abandoned the attempt to find the cause in the will of some one man. Today I would add that we must abandon the attempt to find causes in the will of groups or social classes. Historical movement seems to have its own will, as it were. As individuals, as groups, we can and must make our efforts to influence the direction of this movement, but clearly, we can have only modest expectations. 
So, it seems a mistake to have aspirations for the schools. Due to their relation to the culture they are beyond our control, beyond any group's control. What is not a mistake is to aspire for oneself and for other concrete individuals. What is not a mistake is to care what happens in individuals, and such individuals given our positions are likely to be school people.

With them, we can work to disclose, comprehend, and transform what happens in us, and in them, and derivatively, what happens in schools. Educational practice is not what individuals do in classrooms. It's how they use their experience to move intellectually, to transform themselves.

To focus on schools is to ignore educational experience, is to ignore educational practice. Experience ignored becomes experience forgotten. One becomes numbed to body, to feeling, and so disassociated, one thinks - thinks education is acquisition of information, thinks that evaluation is measurement.

Numbed to experience, the mind functions without anchoring in body and feeling, and as Herman Khan can suggest, nuclear war is not unthinkable. True, 160 million Americans would die, but 60 million would survive.

Such insanity is born in alienation from experience.

Julian Beck in The Life of the Theatre is succinct: "We are feelingless people."

If we could really feel, the pain would be so great that we would stop all the suffering. If we could feel that one person every 6 seconds dies of starvation, and as this is happening, this writing, this reading, someone is dying of starvation, we would stop it.

If we could really feel it in the vows, in the groin, in the throat, in the breast, we would go into the streets and stop the war, stop slavery, stop the prisons, stop the killings, stop destruction.

I might learn what love is.

When we feel, we will feel the emergency. When we feel the emergency, we will act. And when we act, we will then change the world. 